\title{
PENERAPAN METODE AIRDECK UNTUK OPTIMASI DAN EFESIENSI PADA KEGIATAN PELEDAKAN PERTAMBANGAN BATUBARA
}

\author{
Madinatul Arbi ${ }^{1)}$, Muhammad Syafiq Isnaya ${ }^{2)}$, Mahmud ${ }^{3)}$ \\ ${ }^{1)}$ Technical Services Engineer, PT. Multi Nitrotama Kimia \\ ${ }^{2)}$ Graduate Technical Services Engineer, PT. Multi Nitrotama Kimia \\ ${ }^{3)}$ Key Account Manager, PT. Multi Nitrotama Kimia
}

\begin{abstract}
ABSTRAK
PT Multi Nitrotama Kimia merupakan salahsatu perusahaan jasa pertambangan yang bergerak pada bidang penyedia jasa peledakan dan penjualan bahan peledak terbesar di Indonesia, dimana unit usaha ini bekerjasama dengan banyak perusahaan tambang besar dan terkenal di Indonesia. PT Alam Jayabaya Pratama merupakan salahsatu perusahaan besar yang bekerjasama dengan Perusahaan dalam unit usaha jasa peledakan. Sebagai bagian dari perbaikan secara berkelanjutan, perusahaan berupaya mengoptimasi serta memberikan efesiensi kepada proses kegiatan peledakan. Perbaikan hasil fragmentasi dan biaya peledakan menjadi target pada proses perbaikan ini.

Penelitian dan percobaan dilakukan menggunakan beberapa kajian dan pendekatan empiris metode untuk menemukan metode yang bisa mengakomodir target perbaikan. Metode airdeck menjadi pilihan dengan konsep memaksimalkan rambatan gelombang hantaran Work Energy dari bahan peledak dalam lubang (contoh : energi kinetik). Tantangan dan dinamika dalam perbaikan ini adalah berkenaan dengan pemilihan perlengkapan yang menjadi penunjang dalam konsep dan metode airdeck pada rencana perbaikan berkelanjutan ini. Pertimbangan efektifitas dan efesiensi menjadi faktor yang membuat dinamika menjadi menarik.

Metode airdeck yang dikombinasikan dengan pendekatan terkontrol serta efesiensi penggunaan jumlah muatan handak, berhasil menjadi solusi dalam perbaikan hasil peledakan dan efesiensi pada biaya peledakan. Hasilnya, sepanjang tahun 2019 berjalan, perusahaan dapat mengurangi biaya peledakan dan meningkatan hasil peledakan melampaui pada target. Pendekatan analisa dan kontrol bersama tim terkait menghasilkan kerjasama yang baik pada proses perbaikan berkelanjutan ini membantu menyelesaikan dinamika yang terjadi di dalam prosesnya.
\end{abstract}

Kata Kunci : Airdeck, Peledakan, Perbaikan Berkelanjutan

\begin{abstract}
PT Multi Nitrotama Kimia is one of the main mining service companies that move in blasting service and the largest explosives sales service in Indonesia, where the business unit cooperates with many large and well-known mining companies in Indonesia. PT Alam Jayabaya Pratama is one of the major companies that collaborates with the Company in the blasting services business unit. As part of continuous improvement, the company seeks to optimize and provide efficiency to the process of blasting activities. Improvements to the results of fragmentation and blasting costs are targeted in this improvement process.

Research and experiments are carried out using several studies and empirical approaches to find methods that can accommodate improvement targets. The airdeck method is chosen with the concept of maximizing wave propagation work energy from explosives in the hole (example: kinetic energy). The challenges and dynamics in this improvement are related to the selection of equipment that is a support in the airdeck concept and method in this continuous improvement plan. Consideration of effectiveness and efficiency is a factor that makes dynamics attractive.

The airdeck method that combined with a controlled approach and the efficient use of explosive loads, has succeeded in becoming a solution in improving blasting results and efficiency at blasting
\end{abstract}


costs. As a result, throughout 2019, companies can reduce blasting costs and increase blasting results beyond the target. The analysis and control approach with the related team resulted in good cooperation in the process of continuous improvement helping to resolve the dynamics that occurred in the process.

Keywords : Airdeck, Blasting, Continous Improvement

\section{A. PENDAHULUAN}

\section{A.1. Latar Belakang}

Kegiatan penambangan batubara terdiri dari pembongkaran, pemuatan, dan pengangkutan. Salah satu kegiatan pembongkaran dioperasi tambang terbuka adalah pengupasan lapisan tanah penutup. Kegiatan ini didahului dengan proses pemberaian menggunakan metode pengeboran dan peledakan. Peledakan adalah kegiatan pemecahan material dengan menggunakan bahan peledak. Kegiatan peledakan yang dilakukan di tambang batubara adalah untuk memenuhi jumlah overburden terbongkar dan batubara tertambang.

Prediksi jarak lemparan flying rock berperan penting dalam penentuan radius aman alat. Semakin jauh jarak unit untuk evakuasi maka akan semakin besar juga cost yang timbul untuk aktivitas evakuasi unit tersebut baik cost secara langsung seperti fuel consumtion maupun cost tidak langsung seperti pengurangan lifetime undercarriage yg digunakan untuk travel pada saat evakuasi. Seiring dengan kemajuan penambangan, pit yang mulai menyempit ditambah dengan lokasi peledakan yang cukup banyak dan menyebar, alat mulai kesulitan untuk berpindah menuju radius aman, sehingga diperlukan analisis flying rock dari peledakan untuk menentukan radius aman yang sesuai dengan lokasi peledakan untuk melihat apakah radius aman alat saat ini sudah sesuai atau dapat dikurangi.

Adapun yang menjadi lokasi penelitian adalah Pit 7 dan Pit 10 tambang batubara PT. Alamjaya Bara Pratama site Jembayan. Penelitian dilakukan dengan mengukur jarak lemparan maksimum flying rock secara aktual di lapangan.

\section{A.2. Tujuan Perbaikan}

Tujuan dari penggunaan airdeck ini untuk mengurangi penggunaan PF, stemming ejection / flying rock, debu, noice, dengan menggunakan metode airdeck, sehingga energy dari explosives dapat dimanfaatkan dengan lebih maksimal (save explosives cost). Dengan begitu perusahaan dapat mengurangi biaya peledakan dan meningkatan hasil peledakan.

\section{A.3. Problem Analysis}

Geometri peledakan merupakan suatu kegiatan dalam penentuan lokasi lubang ledak dengan tujuan untuk mendapatkan hasil peledakan yang baik sesuai dengan kondisi lapangan yang ada. Untuk burden dan spacing, airdeck berfungsi untuk menghasilkan daya ledak yang lebih kuat dengan geometri peledakan yang ada, sehingga untuk menghindari overbreak, panjang burden dan spacing dapat diperlebar sebesar $10-20 \%$. Penggunaan aplikasi airdeck juga akan berpengaruh terhadap panjang stemming, dikarenakan sebagian ruang untuk stemming disisakan untuk ruang udara, sehingga tinggi stemming menjadi $50-75 \%$ dari peledakan konvensional. 


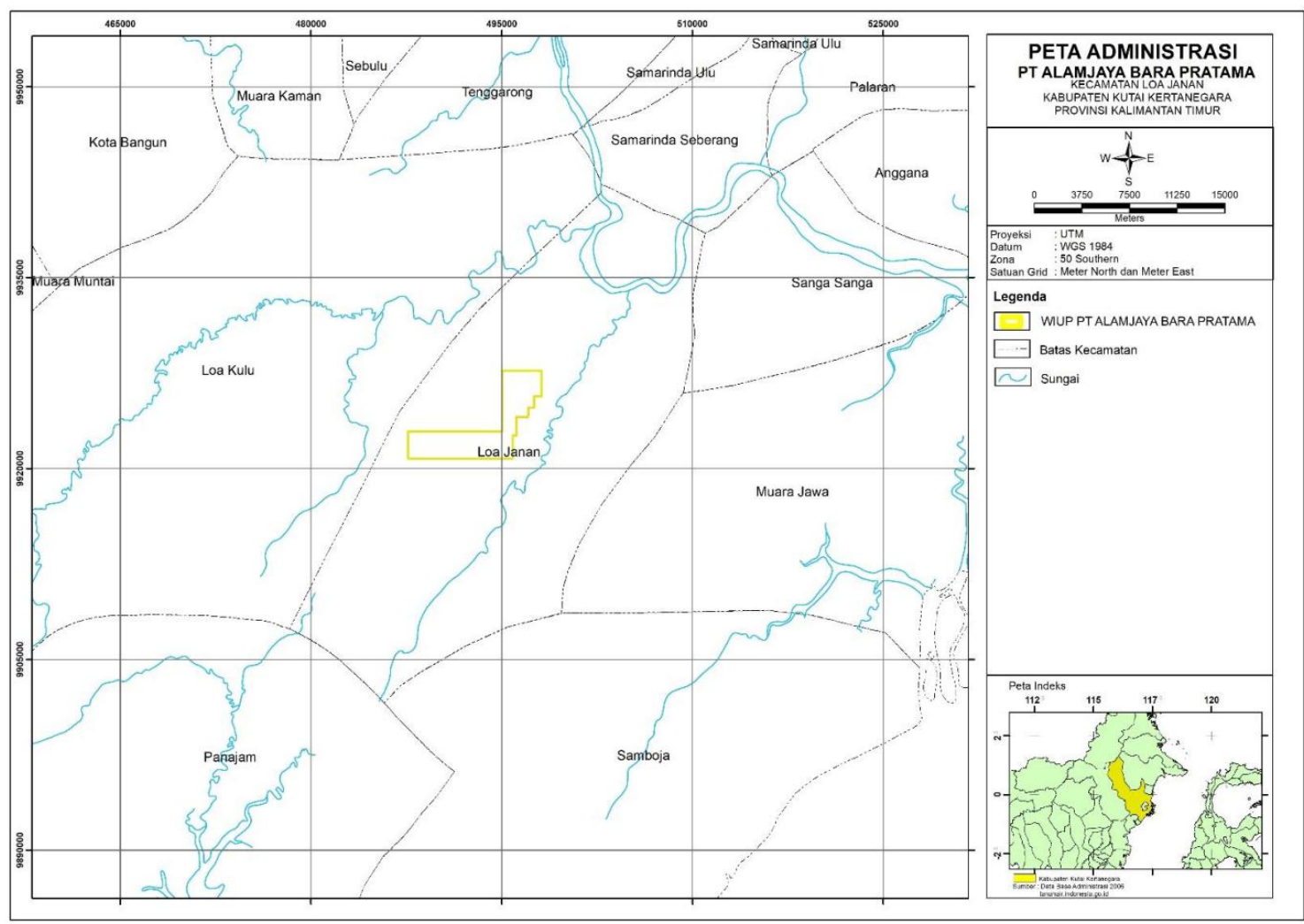

Gambar 1. Peta Administrasi Daerah Penelitian

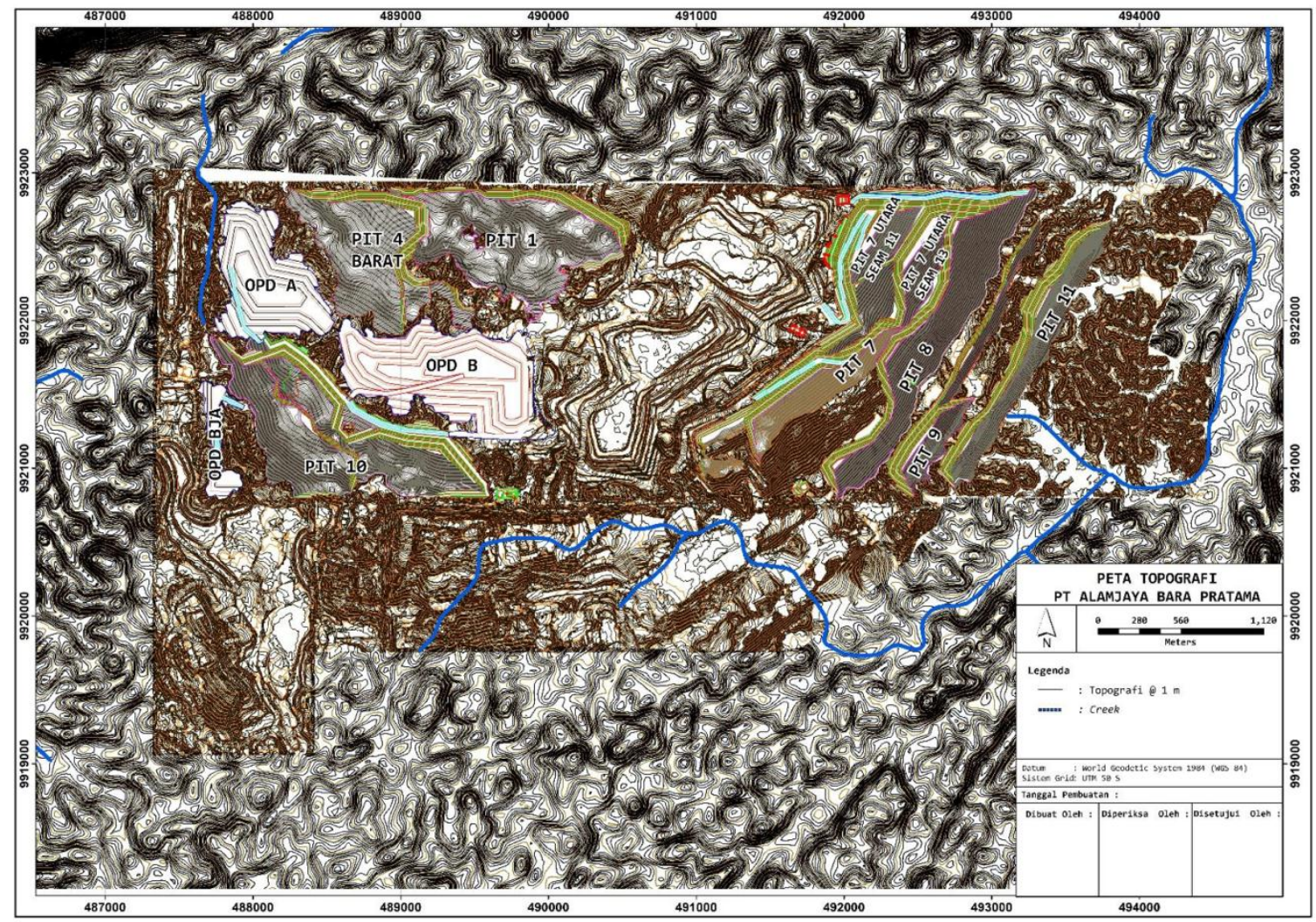

Gambar 2. Area Operasional PT. Alamjaya Bara Pratama

Kolom airdeck sendiri merupakan kolom yang berisi ruang udara dalam lubang ledak. Pengaruh airdeck terhadap kolom isian yaitu pengurangan jumlah bahan peledak yang sesuai dengan 
kebutuhan sehingga kebutuhan bahan peledak dapat dikurangi tanpa merubah performa dari peledakan itu sendiri. Pengurangan bahan peledak maksimal dalam peledakan airdeck yaitu sebesar $20 \%$, dengan begitu penggunaan metode airdeck terhadap panjang kolom isian (PC) akan semakin kecil dikarenakan bahan peledak yang digunakan berkurang sekitar $20 \%$.

\section{B. PERBAIKAN (IMPROVEMENT)}

\section{B.1. Aplikasi Penggunaan Airdeck}

Pada pembahasan sebelumnya, diketahui penggunaan aplikasi airdeck akan berpengaruh terhadap geometri peledakan sehingga penggunaan airdeck harus dilakukan sesuai dengan geometri yang telah ditentukan. Adapun beberapa perlengkapan yang digunakan pada kegiatan peledakan di PT. Alamjaya Bara Pratama untuk membuat metode airdeck terhadap kolom isian sebagai berikut:

1) Stick

Stick yang di gunakan dalam metode airdeck ini terbuat dari kayu dengan ukuran PxLxT = $30 \mathrm{~cm} \times 7 \mathrm{~cm} \times 5 \mathrm{~cm}$, stick ini berfungsi sebagai penahan bola airdeck di atas lubang ledak yang dikaitkan mengunakan tali yang di hubungkan dengan bola airdeck.

\section{2) Tali}

Tali yang digunakan dalam metode ini adalah jenis tali yang kuat namun berukuran kecil, tali yang di gunakan dalam hal ini adalah tali tambang tampar yang berukuran $5-10 \mathrm{~mm}$. Tali ini mampu menahan beban material steaming dan tidak mudah putus saat terkena cangkul dari kegiatan steming. Tali ini berfungsi sebagai pengkait terhadap bola airdeck, dan tali ini juga digunakan sebagai ukuran untuk menetukan kedalaman stemming yang di inginkan.

3) Bola Airdeck

Airdeck yang digunakan berbentuk bola. Bola ini terbuat bahan plastik yang kuat dan mempunyai lubang di tengahnya sebagai jalan masuknya air jika steaming di dalam lubang yang berair. Bola yang di gunakan di Jobsite PT. Alamjaya Bara Pratama ini berdiameter $180 \mathrm{~mm}$, bola ini berfungsi untuk menyumbat material stemming dikedalaman yang di inginkan.

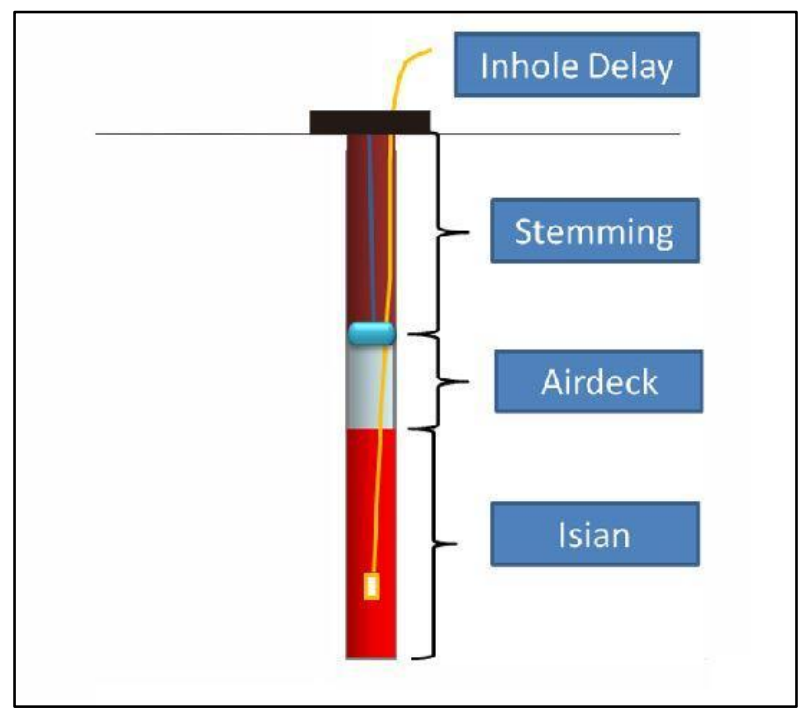

Gambar 3. Posisi Airdeck

\section{B.2. Pengambilan Sample}

Pengambilan sample dilakukan dengan melakukan beberapa pengumpulan data, mulai dari data primer, data alat mekanis dan data sekunder. 
Data primer dengan melakukan pengukuran geometri peledakan meliputi pengukuran burden (B), spacing $(\mathrm{S})$, stemming $(\mathrm{St})$, kedalaman $(\mathrm{H})$, burden awal $(\mathrm{Ba})$, dan kolom isian $(\mathrm{PC})$.

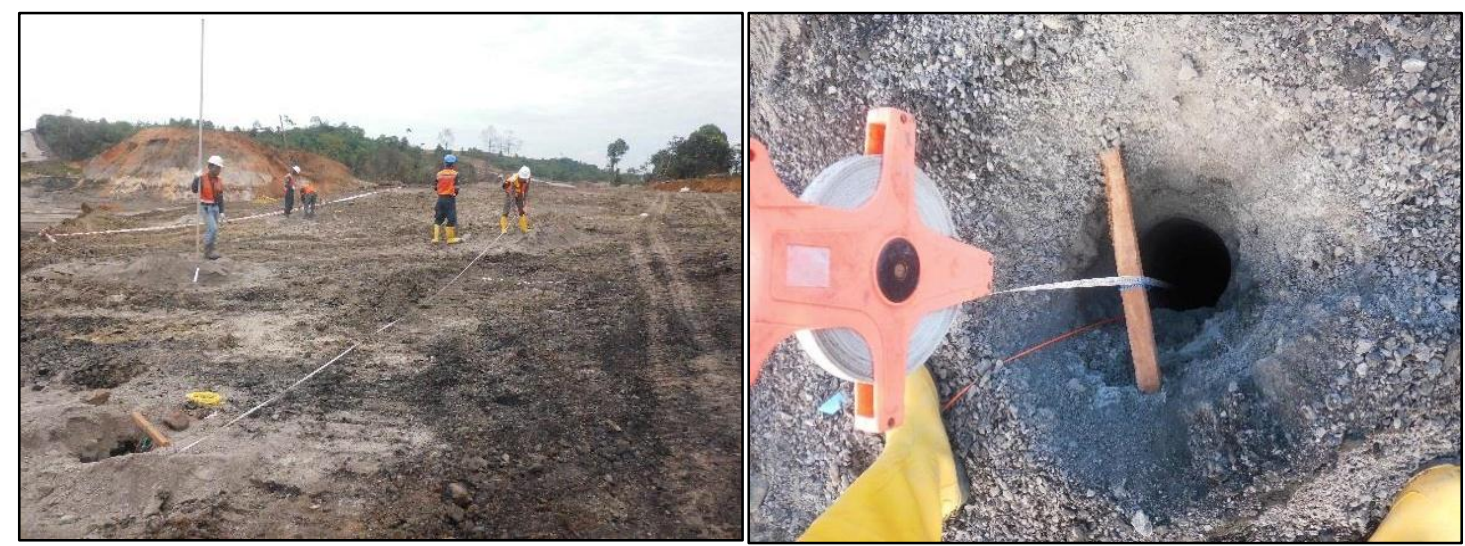

Gambar 4. Foto Pengukuran

Tabel 1. Rata-Rata Geometri Peledakan Lokasi Pit 7 Utara

\begin{tabular}{ccccccccc}
\hline No & Date & Location & B $(\mathbf{m})$ & S $(\mathbf{m})$ & St $(\mathbf{m})$ & PC $(\mathbf{m})$ & Ba $(\mathbf{m})$ & H $(\mathbf{m})$ \\
\hline 1 & $20 / 12 / 2018$ & Pit 7 Utara & 7,55 & 8,44 & 4,38 & 1,90 & 3,75 & 7,65 \\
2 & $21 / 12 / 2018$ & Pit 7 Utara & 7,47 & 8,80 & 3,38 & 1,65 & - & 6,46 \\
3 & $22 / 12 / 2018$ & Pit 7 Utara & 7,48 & 8,61 & 2,88 & 1,56 & 4,33 & 6,27 \\
4 & $27 / 12 / 2018$ & Pit 7 Utara & 7,73 & 8,74 & 4,73 & 2,26 & 4,56 & 8,01 \\
5 & $02 / 01 / 2019$ & Pit 7 Utara & 7,75 & 8,77 & 3,77 & 1,98 & 4,25 & 7,61 \\
6 & $03 / 01 / 2019$ & Pit 7 Utara & 7,56 & 8,78 & 3,47 & 1,61 & 4,14 & 6,11 \\
7 & $05 / 01 / 2019$ & Pit 7 Utara & 7,50 & 8,77 & 2,61 & 1,71 & 3,24 & 6,19 \\
8 & $07 / 01 / 2019$ & Pit 7 Utara & 7,74 & 8,64 & 3,71 & 2,00 & 4,20 & 7,26 \\
9 & $08 / 01 / 2019$ & Pit 7 Utara & 7,63 & 8,66 & 4,18 & 2,20 & 3,73 & 8,09 \\
10 & $09 / 01 / 2019$ & Pit 7 Utara & 7,63 & 8,71 & 3,80 & 2,03 & - & 7,09 \\
11 & $10 / 01 / 2019$ & Pit 7 Utara & 7,47 & 8,65 & 4,12 & 2,13 & - & 7,90 \\
12 & $11 / 01 / 2019$ & Pit 7 Utara & 7,41 & 8,58 & 3,77 & 2,13 & 4,12 & 7,63 \\
13 & $14 / 01 / 2019$ & Pit 7 Utara & 7,74 & 8,79 & 4,70 & 2,45 & - & 8,32 \\
14 & $15 / 01 / 2019$ & Pit 7 Utara & 7,64 & 8,73 & 4,32 & 2,34 & - & 7,94 \\
15 & $16 / 01 / 2019$ & Pit 7 Utara & 7,57 & 8,78 & 4,43 & 2,39 & - & 8,19 \\
16 & $17 / 01 / 2019$ & Pit 7 Utara & 7,42 & 8,63 & 4,54 & 2,35 & 3,85 & 8,23 \\
17 & $22 / 01 / 2019$ & Pit 7 Utara & 7,03 & 8,77 & 4,36 & 2,37 & 5,22 & 8,23 \\
18 & $23 / 01 / 2019$ & Pit 7 Utara & 6,76 & 8,63 & 4,65 & 2,30 & 3,83 & 8,25 \\
19 & $24 / 01 / 2019$ & Pit 7 Utara & 7,67 & 8,70 & 4,33 & 2,41 & - & 7,97 \\
\hline
\end{tabular}

Tabel 2. Rata-Rata Geometri Peledakan Lokasi Pit 10

\begin{tabular}{ccccccccc}
\hline No & Date & Location & B (m) & S (m) & St (m) & PC (m) & Ba (m) & H(m) \\
\hline 1 & $23 / 12 / 2018$ & Pit 10 & 7,60 & 8,84 & 4,67 & 2,14 & - & 8,29 \\
2 & \multirow{2}{*}{$24 / 12 / 2018$} & Pit 10 & \multirow{2}{*}{7,78} & 8,74 & 4,67 & 2,22 & - & 8,53 \\
\hline
\end{tabular}




\begin{tabular}{ccccccccc}
\hline 3 & $26 / 12 / 2018$ & Pit 10 & 7,71 & 8,63 & 4,65 & 2,10 & - & 8,06 \\
4 & $04 / 01 / 2019$ & Pit 10 & 7,63 & 8,67 & 2,45 & 1,33 & 3,51 & 5,18 \\
5 & $12 / 01 / 2019$ & Pit 10 & 7,48 & 8,64 & 4,33 & 2,33 & 3,35 & 8,22 \\
6 & $13 / 01 / 2019$ & Pit 10 & 7,50 & 8,71 & 4,36 & 2,11 & 3,59 & 8,31 \\
7 & $18 / 01 / 2019$ & Pit 10 & 7,65 & 8,79 & 4,36 & 2,07 & 3,67 & 7,97 \\
8 & $19 / 01 / 2019$ & Pit 10 & 7,95 & 8,84 & 4,15 & 2,40 & 4,56 & 8,23 \\
9 & $20 / 01 / 2019$ & Pit 10 & 7,56 & 8,77 & 3,69 & 2,04 & 4,23 & 7,50 \\
10 & $21 / 01 / 2019$ & Pit 10 & 7,56 & 8,79 & 3,22 & 1,40 & 5,22 & 5,50 \\
11 & $25 / 01 / 2019$ & Pit 10 & 7,70 & 8,72 & 4,45 & 2,21 & 3,40 & 8,00 \\
\hline
\end{tabular}

Pengambilan data alat mekanis di lokasi peledakan dilakukan dengan mencatat alat mekanis apa saja yang berada di dekat lokasi peledakan yang terganggu ketika peledakan berlangsung dan harus melakukan evakuasi. Tetapi tidak termasuk HD (Hauling Dumptruck) dan DT (Dumptruck), dikarenakan kegiatan peledakan berlangsung pada jam istirahat dan alat-alat tersebut pada saat peledakan berlangsung berada di lokasi istirahat sehingga tidak terpengaruh jika radius aman peledakan dikurangi.

Data sekunder merupakan data yang telah ada dan diperoleh dari perusahaan atau studi literatur, diantaranya:

1. Peta lokasi penambangan PT Alamjaya Bara Pratama

2. Spesifikasi kecepatan dan fuel consumption alat mekanis penambangan

\section{B.3. Analisa Metode Airdeck}

\section{a. Simulasi Tinggi Stemming dan Airdeck}

Dikarenakan standar deviasi terkecil didapatkan oleh teori Richard and Moore tipe cratering, maka teori tersebut digunakan dalam simulasi tinggi stemming dan airdeck beserta aturan-aturannya. Pada gambar 3.20, Richard and Moore mengeluarkan aturan tentang safety factor yang isinya "Safety factor 2 untuk alat" dan "Safety factor 4 untuk manusia". Artinya radius aman untuk alat mekanis minimal harus 2 kali dari lemparan flying rock terjauh, sedangkan radius aman untuk manusia minimal harus 4 kali lemparan flying rock terjauh. Sehingga untuk memenuhi permintaan perusahaan agar radius aman peledakan dapat dikurangi menjadi menjadi $200 \mathrm{~m}$, prediksi lemparan flying rock maksimum harus $100 \mathrm{~m}$.

\section{B.4. Skala Pengisian (Scaled Depth of Burial)}

Skala pengisian merupakan kajian yang menyatakan seberapa besar suatu peledakan dapat terkontrol. Scaled Depth of Burial (SDoB) untuk geometri aktual menghasilkan nilai dengan rata rata $1,26 \mathrm{~m} / \mathrm{kg} 1 / 3$. Angka masuk dalam kategori "controlled energy" yang mana menghasilkan ledakan dengan fragmentasi yang bagus, volume batuan yang terberai maksimum, vibrasi dan airblast masih dapat diterima, pengngkatan batuan yang bagus dan tumpukan batuan yang menggunung.

\section{B.3. Perhitungan Fragmentasi Batuan}

Berdasarkan pehitungan fragmentasi batuan persamaan Quznetsov, fragmentasi batuan geometri aktual, simulasi geometri 1 dan 2 memiliki hasil yang sama. Dikarenakan parameter geometri yang dirubah pada simulasi geometri 1 dan 2 tidak ada hubungan dengan perhitungan fragmentasi Quznetsov. Besar fragmentasi batuan berdasarkan rumus Quznetsov memiliki ukuran rata - rata $70,76 \mathrm{~cm}$ yang jika dibandingkan dengan ukuran bucket alat muat terkecil untuk overburden (PC1250) yaitu sebesar $2,53 \mathrm{~m} \times 2.42 \mathrm{~m}$, maka ukuran fragmentasi batuan tersebut cukup ideal untuk pemuatan. 


\section{HASIL \& EVALUASI}

Dari simulasi perubahan tinggi stemming dan tinggi airdeck yang dilakukan, simulasi geometri 1 (tinggi airdeck $-0.65 \mathrm{~m}$ dan tinggi stemming $+0.65 \mathrm{~m}$ ) menghasilkan lemparan flying rock terjauh sebesar 99,67 sedangkan simulasi geometri 2 (tinggi airdeck $+0.65 \mathrm{~m}$ dan inggi stemming $-0.65 \mathrm{~m}$ ) menghasilkan lemparan flying rock terjauh sebesar 409,66 m. Berdasarkan hasil tersebut simulasi geometri 1 dipilih sebagai rekomendasi geometri peledakan, karena jarak lemparan flying rock terjauh memenuhi syarat agar pengurangan radius aman untuk alat mekanis dapat dilakukan $300 \mathrm{~m}$ menjadi $200 \mathrm{~m}$.

Berdasarkan analisa simulasi geometri peledakan dipilih simulasi geometri 1 sebagai gemetri yang akan dijadikan rekomendasi. Dari segi SDoB simulasi geometri 1 cukup bagus karena berada pada rentang "controlled energy" dan "very controlled energy"

Pengurangan jarak radius aman dari 300 m menjadi $200 \mathrm{~m}$ akan memperkecil jarak evakuasi alat mekanis pada saat peledakan berlangsung (gambar 4.18). Dengan berkurangnya jarak evakuasi, maka akan berkurang pula waktu pada saat evakuasi berlangsung. Dengan demiakian akan berkurang juga pengggunaan bahan bakar yang digunakan

\begin{tabular}{|c|c|c|c|c|c|c|c|c|c|c|}
\hline \multirow[t]{2}{*}{ Jenis Alat } & \multirow{2}{*}{$\begin{array}{l}\text { Rata - } \\
\text { Rata } \\
\text { Jumlah } \\
\text { Alat }\end{array}$} & $\begin{array}{l}\text { Kecepatan } \\
\text { Alat }\end{array}$ & $\begin{array}{l}\text { Waktu } \\
\text { Travel } \\
300 \mathrm{~m}\end{array}$ & $\begin{array}{l}\text { Waktu } \\
\text { Travel } \\
200 \mathrm{~m}\end{array}$ & $\begin{array}{c}\text { Efisiensi } \\
\text { Waktu } \\
\text { Travel }\end{array}$ & $\begin{array}{l}\text { Penggunaan } \\
\text { Bahan Bakar }\end{array}$ & $\begin{array}{c}\text { Efisien si } \\
\text { Bahan } \\
\text { Bakar }\end{array}$ & $\begin{array}{c}\text { Efisiensi Biaya } \\
\text { Bahan Bakar }\end{array}$ & \multicolumn{2}{|c|}{ Efisiensi Biaya } \\
\hline & & (m/min) & (min) & (min) & (min) & (Itr/min) & (Itr) & $\mathrm{Rp}$ & \multicolumn{2}{|c|}{$\mathrm{Rp}$} \\
\hline PC 2000 & 1,0 & 23,00 & 13,04 & 8,70 & 4,35 & 2,30 & 10,02 & 103.180 & Rp & 206.359 \\
\hline PC 1250 & 0,7 & 35,00 & 8,57 & 5,71 & 2,86 & 1,70 & 4,85 & 49.953 & $\mathrm{Rp}$ & 73.265 \\
\hline PC 400 & 0,7 & 40,00 & 7,50 & 5,00 & 2,50 & 0,61 & 1,52 & 15.607 & $\mathrm{Rp}$ & 21.849 \\
\hline PC 300 & 0,8 & 75,00 & 4,00 & 2,67 & 1,33 & 0,64 & 0,86 & 8.812 & $\mathrm{Rp}$ & 13.512 \\
\hline PC 200 & 0,8 & 68,33 & 4,39 & 2,93 & 1,46 & 0,37 & 0,54 & 5.602 & $\mathrm{Rp}$ & 8.590 \\
\hline DZ 85 & 0,7 & 101,67 & 2,95 & 1,97 & 0,98 & 0,64 & 0,63 & 6.484 & Rp & 9.510 \\
\hline DZ 155A & 0,8 & 95,00 & 3,16 & 2,11 & 1,05 & 0,83 & 0,88 & 9.035 & $\mathrm{Rp}$ & 15.058 \\
\hline D245S & 0,5 & 56,33 & 5,33 & 3,55 & 1,78 & 1,09 & 1,93 & 19.899 & $\mathrm{Rp}$ & 19.899 \\
\hline & & & & & & \multicolumn{3}{|c|}{ Efisiensi Biaya / lokasi Blasting } & $\mathrm{Rp}$ & 348.144 \\
\hline & & & & & & \multicolumn{3}{|c|}{ Efisiensi Biaya 1 tahun } & $\mathrm{Rp}$ & 191.827 .294 \\
\hline
\end{tabular}

\section{KESIMPULAN}

Berdasarkan pembahasan yang telah dijelaskan sebelumnya, dapat disimpulkan sebagai berikut :

1) Berdasarkan analisis statistik antara geometri peledakan airdeck terhadap lemparan aktual, didapatkan beberapa parameter geometri peledakan yang berpengaruh kuat terhadap lemparan flying rock, yaitu :

- Tinggi airdeck dengan nilai koefisien korelasi (R) sebesar 0,634

- Tinggi stemming dengan nilai koefisien korelasi (R) sebesar 0,606

- Jarak burden awal dengan nilai koefisien korelasi (R) sebesar 0,605

2) Rekomendasi geometri peledakan airdeck yang tepat untuk memenuhi syarat dalam pengurangan radius aman alat mekanis dari $300 \mathrm{~m}$ menjadi 200 yaitu:

- Jarak burden awal minimal sebesar 3,25 m dan maksimal $4 \mathrm{~m}$.

- Ketinggian stemming ditambah 0,65 m dari ketinggian iaktual

- Ketinggian airdeck dikurangi 0,65 m dari ketinggian airdeck aktual.

3) Efisiensi bahan bakar dari pengurangan radius aman alat mekanis dari $300 \mathrm{~m}$ menjadi $200 \mathrm{~m}$ didapatkan nilai penghematan sebesar Rp 348.144 / lokasi peledakan. Jika dikalikan jumlah lokasi peledakan / tahun penghematan biaya bahan bakar solar sebesar Rp 191.827.294. 


\section{UCAPAN TERIMA KASIH}

Penulis ingin mengucapkan terima kasih kepada PT. Alamjaya Bara Pratama sebagai pelanggan PT.Multi Nitrotama Kimia yang memberikan dukungan dan persetujuan mereka untuk menerbitkan makalah ini.

\section{DAFTAR PUSTAKA}

Ash, R. L. 1990. "Design of Blasting Round Surface Mining". B. A. Kennedy Editor, Society for Mining, Metallurgy, and Explotion, Inc.

Chappetta, R. F. 2004. "New Blasting Technique to Eliminate Subgrade Drilling, Improve Fragmentation, Reduce Explosive Consumption and Lower Ground Vibration".

Chunningham, C.V.B. 1983. "The Kuz-Ram Model for Prediction of Fragmentation from Blasting". Sweden: Symposium on Rock Fragmentation by Blasting.

Ghasemi, Ibarhim. 2012. "Development of an Empirical Model for Predicting The Effects of Controllable Blasting Parameters on Flying rock Distance in Surface Mines". International Journal of Rock Mechanic and Mining Sciences : Brookfield

Lubis, Herri. 2015. "Aplikasi Air Deck dalam Mengoptimalkan Blasting Performance".

Lunborg. 1981. "The Probability of Fly Rock". Sve De Fo Report. DS 1981.

McLaughlin, Pat. 1893. "Appplication of Air Deck in Surface Blasting". Tanzania: Case Study Barrick Gold.

Mel'nikov, N. V., and Marchenko, L. N. 1971. "Effective Methods of Appl- ication of Explotion Energy ini Mining and Construction". New York: AIME.

Mel'nikov, N. V., and Marchenko, L. N., Seinov, N. O., and Zarikov , I. K. 1979. "Method of Enhanced Rock Blasting by Blasting”. New York: AIME. 